\title{
A darker chromatic variation of Rhodnius pallescens infected by specific genetic groups of Trypanosoma rangeli and Trypanosoma cruzi from Panama
}

\author{
Azael Saldaña ${ }^{1,2}$, Ana María Santamaría', Vanessa Pineda ${ }^{1}$, Vanessa Vásquez ${ }^{1}$, Nicole L. Gottdenker ${ }^{3}$
} and José E. Calzada ${ }^{1 *}$

\begin{abstract}
Background: Rhodnius pallescens, the only species of this genus reported in Panama, has a wide geographical distribution and is associated with most cases of Chagas disease and human infections with Trypanosoma rangeli in this country. Thus far, no phenotypic variants of this triatomine have been registered. Similarly, genotyping of the trypanosomes that infect this vector has only been partially evaluated.

Results: A total of 347 specimens of R. pallescens were collected in Attalea butyracea palm trees located near a mountainous community of the district of Santa Fe, province of Veraguas. Bugs were slightly longer and had a darker coloration compared to that reported for this species. Infection rates for trypanosomes performed with three PCR analyses showed that $41.3 \%$ of the adult triatomines were positive for T. cruzi, 52.4\% were positive for T. rangeli and $28.6 \%$ had mixed T. cruzi/T. rangeli infections. Based on cox2 analysis, Tcl was the single T. cruzi discrete typing unit (DTU) detected, and a genetic variant of KP1(-)/lineage $C$ was the only genetic group found for $T$. rangeli.

Conclusions: A darker chromatic variation of $R$. pallescens predominates in a mountainous region of Panama. These triatomines show high trypanosome infection rates, especially with $T$. rangeli. Regarding $T$. rangeli genetic diversity, complementary studies using other molecular markers are necessary to better define its phylogenetic position.
\end{abstract}

Keywords: Rhodnius pallescens, Trypanosoma cruzi, Trypanosoma rangeli, Genotyping, Panama

\section{Background}

Human infection with Trypanosoma cruzi and/or Trypanosoma rangeli has been reported in different regions of the Republic of Panama [1]. Trypanosoma cruzi is the causal agent of Chagas' disease, a zoonosis most commonly associated in Panama with heart sickness [2]. Trypanosoma rangeli is a parasite not linked to pathological processes in humans [3], but with clinical and epidemiological importance due primarily to its antigenic similarity with T. cruzi [4]. Both trypanosomes are transmitted by triatomine bugs (Reduvidae: Triatominae) of wide distribution in different habitats throughout the country

\footnotetext{
* Correspondence: jcalzada@gorgas.gob.pa

${ }^{1}$ Instituto Conmemorativo Gorgas de Estudios de la Salud (ICGES), Ciudad de Panamá, Panamá

Full list of author information is available at the end of the article
}

[5]. Rhodnius pallescens is the main vector of T. cruzi and T. rangeli in Panama [1]. The principal biotope for $R$. pallescens is the crown of the "royal palm" (Attalea butyracea), from where it frequently moves to nearby dwellings.

Intraspecific genetic variability has been described in both $T$. cruzi and T. rangeli isolates using several molecular markers [3, 6]. Genotyping of these hemoparasites, as well as the study of the biological variants adopted by their vectors in an endemic region, is important to achieve the understanding, surveillance and management of particular eco-epidemiological scenarios of Chagas' disease. In this report, we describe phenotypic characteristics of a darker chromatic population of $R$. pallescens, infection rates, and trypanosome genotypes that infect this melanic variant. 


\section{Methods}

The study took place in a rural Panamanian community called La Culaca $\left(8^{\circ} 31^{\prime} 0^{\prime \prime} \mathrm{N}, 81^{\circ} 2^{\prime} 60^{\prime \prime} \mathrm{W}, 698 \mathrm{masl}\right)$, located in the Northern region of the Veraguas Province, Santa Fe District, in the western half of the Isthmus of Panama. This region was recently described as a new focus of Chagas disease in Panama [7]. Triatomine bugs were captured during dissection of nine $A$. butyracea palm trees located less than $100 \mathrm{~m}$ from inhabited community dwellings. Palms were cut down by their owners for agricultural activities, collection of leaves for roofing, and/or preparation of "palm wine". The number of bugs was counted from each palm, and developmental stage, species and morphological characteristics such as length and coloring patterns were described for each individual triatomine collected.

The DNA of the adult triatomines was extracted from the whole vector according to a methodology previously described that has proven to be efficient for further molecular analysis [8]. To evaluate natural trypanosome infections, two independent PCR analyses based on genes encoding for H2A/SIRE (TcH2AF/R) and sno-RNA-C11 (TrF/R2) were carried out [9]. The primers TcH2AF/R and TrF/R2 amplify $234 \mathrm{bp}$ and $620 \mathrm{bp}$ fragments for $T$. cruzi and $T$. rangeli, respectively. In addition, a restriction fragment length polymorphism (RFLP) analysis based on the cytochrome $c$ oxidase subunit 2 gene (PCR/RFLP-cox2) was used for the simultaneous detection and typing of $T$. rangeli major genetic groups and T. cruzi discrete typing units (DTUs) [10]. PCR-cox2 products from $8 T$. rangeli and $9 T$. cruzi single infections were further purified and sequenced using the same primers. Sequences were edited and compared with retrieved reference sequences representing each $T$. rangeli major genetic group and T. cruzi DTUs in GenBank by Basic Local Alignment Search Tool (BLAST) queries.

\section{Results and discussion}

All palms were infested with $R$. pallescens. In total, 347 specimens were collected, including 63 adults and 284 nymphs (16 fifth-instar, 90 fourth-instar, 113 third-instar, 52 second-instar and 13 first-instar). All fifth-, fourthand third-stage nymphs were examined by microscopy for trypanosome infection. We did not test first- and second-stage nymphs due to the technical difficulty to process individually these specimens for microscopic examination.

Of the 63 adults, 38 were males (60.3\%) and 25 females (39.7\%). Adult bugs had a darker coloration and an average length slightly longer (22-24 mm for males and 22.5-25 $\mathrm{mm}$ for females) than the standard established for this species [11] (Fig. 1). Rectangular spots of dorsal connexival plates, an important morphological characteristic of $R$. pallescens [11], were clearly distinguishable. However, the legs of both adults and nymphs were uniformly blackish. The mottled pattern typically described for $R$. pallescens legs was not observed (Fig. $1)$. Three $(4.8 \%)$ of the adult bugs collected were completely dark, with a pronotum entirely black and the abdomen with an under surface of a general dark brown color (Fig. 1).

Infection rates for trypanosomes detected by microscopy in fifth-, fourth- and third- instar nymphs were $18.8 \%, 58.9 \%$ and $64 \%$, respectively. Due in part to economic constraints, we focused our molecular analysis in adult specimens, which for this particular sylvatic species have a major vector relevance in the domestic transmission scenario. In adult bugs, infection rates for trypanosomes were performed using three PCR analyses (TcH2AF/R, TrF/R2 and PCR/RFLP-cox2). The combined results showed that $41.3 \%(26 / 63)$ of the adult triatomines were positive for $T$. cruzi, 52.4\% (33/63) were positive for $T$. rangeli and $28.6 \%(18 / 63)$ had mixed T. cruzi/T. rangeli infection. The rate of single infections was lower; $14.3 \%$ (9/63) were positive for T. cruzi only

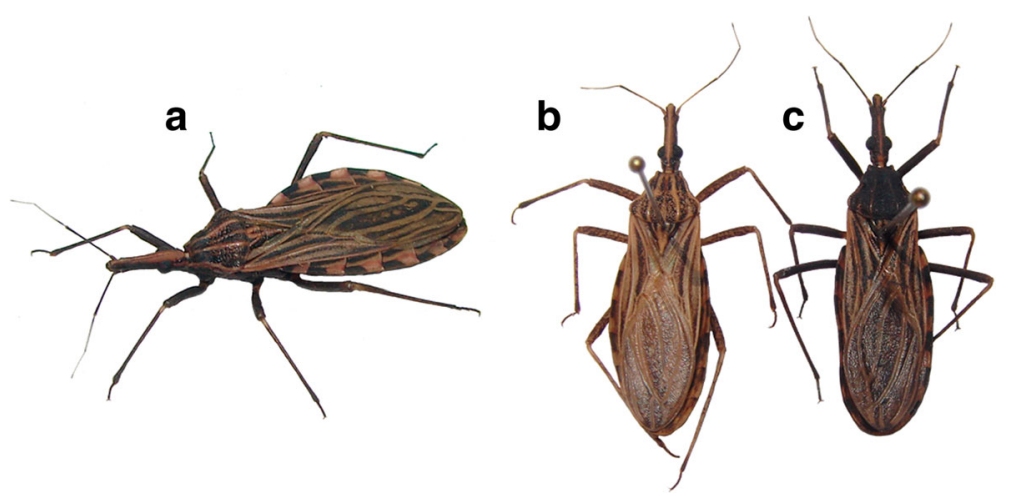

Fig. 1 Chromatic variations of Rhodnius pallescens in Panama. a Common darker specimen from Santa Fe, Veraguas Province, Panamá. b Specimen with a typical coloration found in other Chagas disease endemic regions. c Completely dark specimen from Santa Fe, Panamá 
and $22.2 \%(14 / 63)$ were singly infected with $T$. rangeli. Twenty-two (34.9\%) triatomines did not have trypanosome infections. Trypanosoma rangeli and T. cruzi infections were genotyped by PCR/RFLP-cox 2 and confirmed by sequencing PCR-cox 2 amplicons. Trypanosoma cruzi lineage I (TcI) was the single $T$. cruzi discrete typing unit (DTU) detected, and $\mathrm{KP} 1(-) /$ lineage $\mathrm{C}$ was the only genetic group found for T. rangeli (Figs. 2, 3). Interestingly, the phylogenetic relationships assessed by cox 2 partial sequencing confirmed that $T$. rangeli isolates from this Panamanian region were more closely related to KP1(-); however, they all grouped in a separate clade independently of the KP1(-) reference strain (Fig. 3).

So far, 21 species of Rhodnius have been described [13], almost all of them are associated with palm tree habitats. Rhodnius pallescens infestation rates in $A$. butyracea palms from Panama are the highest reported among triatomines infesting palms throughout Latin America [12]. This was also demonstrated in the search conducted during the present study, where $100 \%$ of the palms evaluated were infested with this triatomine. Even though the chromatic patterns are useful for Rhodnius species identification [11], some interspecific chromatic variations have been reported for this species [14-16], as in other triatomine groups [17-19]. However, as far as we know, there were no reports of chromatic differences in $R$. pallescens. In this species, the typical specimens show a general yellowish brown color with dark brown spots, in many cases dotted lighter [11] (Fig. 1). The occurrence of a darker chromatic variation of $R$. pallescens observed in the mountainous region of Santa Fe, Panama (Fig. 1) could be an example of how the biotope inhabited by this species can influence its coloration. This melanic bugs blends perfectly with the wet crowns of $A$. butyracea, common of this rainy region with cooler temperatures compared to other areas where $R$. pallescens has been reported in Panama. This adaptive character (camouflage) for a darker habitat could be very useful to avoid natural predators present in these palms. The larger average size of these bugs could also be considered a particular adaptation to this ecological niche. In this regard, the difference in coloration has been considered as an important trait for the recent descriptions of two new Rhodnius species [13, 20]. Nevertheless, additional genetic, morphometric, cross-breeding and geographical distribution studies are needed to clarify whether the darker variant of $R$. pallescens from Santa Fe represents a different phenotypic variation of the typical specimens or a distinct species. It is also important to mention that no typical specimens of $R$. pallescens have yet been found in Santa Fe region.

Another objective of this study was to determine the infection rates and genetic diversity of the trypanosome populations that are circulating in the darker variation of $R$. pallescens described above. The rate of infection with $T$. rangeli and/or $T$. cruzi was high $(65.1 \%)$ in the dark specimens, similar to other investigations from Panama that evaluated infection index with trypanosomes in R. pallescens $[8,21,22]$. It is interesting to note that the infection rate with $T$. cruzi was lower (41.3\%) than that reported for $R$. pallescens collected from others endemic areas in Panama $[8,22]$. However, the rate found for the infection with $T$. rangeli is one of the highest reported in Panama and other regions where this

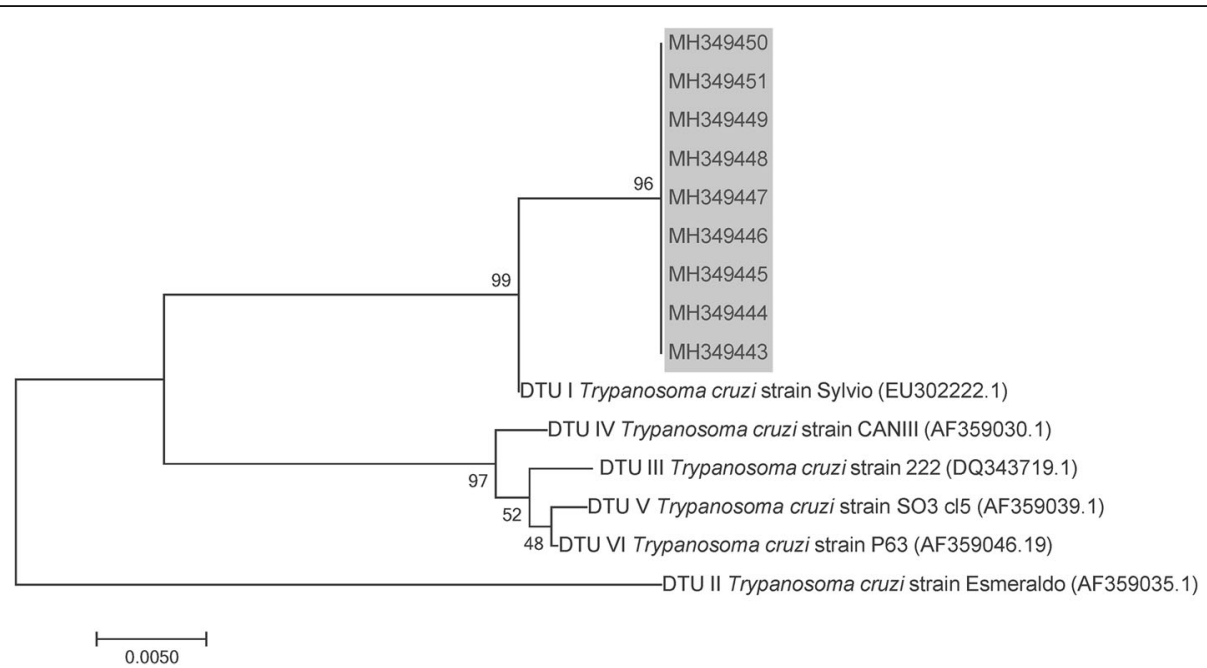

Fig. 2 Phylogenetic positioning of Trypanosoma cruzi parasites found in a darker chromatic variation of Rhodnius pallescens from Santa Fe, Veraguas Province, Panamá. The phylogenetic tree is based on cytochrome c oxidase subunit 2 sequences. The trees were constructed using the neighbor-joining method and numbers on the tree indicate bootstrap values for branch points. The analyses included reference sequences of $T$. cruzi discrete typing units (DTUs) (accession numbers in parentheses). The gray shaded portion of the tree corresponds to the sequences generated in this study 


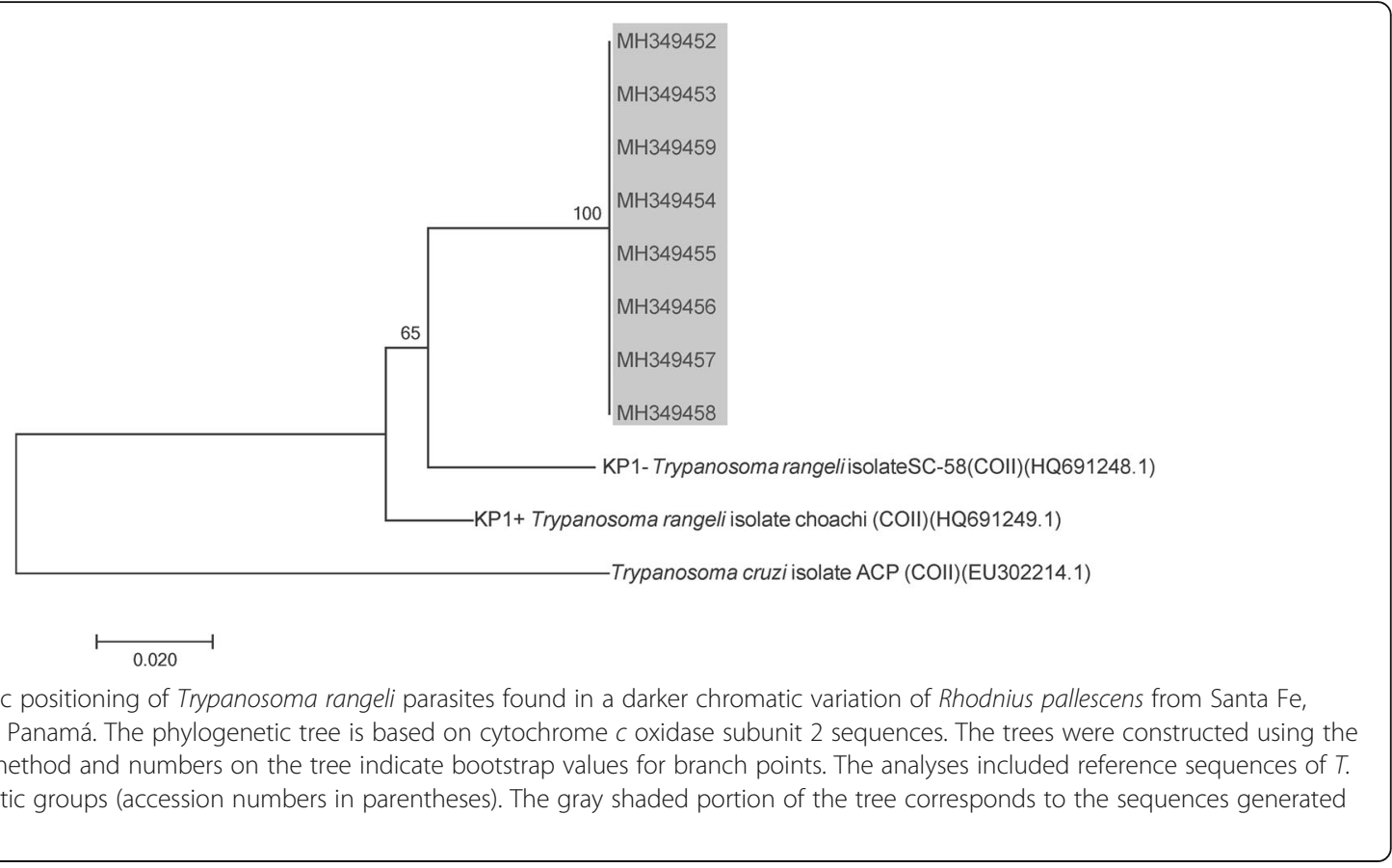

parasite has been described [9, 23-25]. These high infection frequencies with $T$. rangeli seem to be inconsistent with the described pathological effects of $T$. rangeli for its vectors [26]. Recently, Peterson \& Graham [27] also called attention to the lack of sufficient evidence to support the assumption that $T$. rangeli is pathogenic to all Rhodnius species. On the other hand, Gottdenker et al. [28] postulated that $T$. rangeli/T. cruzi co-infection may confer a survival advantage for $R$. pallescens throughout adulthood. The same conclusion was reached by Peterson \& Graham [27] who observed that $R$. prolixus experimentally co-infected with $T$. cruzi and $T$. rangeli have higher survival than bugs infected with just one of the species. In any case, a better evaluation of the occurrences and consequences of the infection with $T$. cruzi and/or $T$. rangeli in the dark variant of $R$. pallescens is necessary. Regarding trypanosome genetic diversity, TcI was the only DTU detected for T. cruzi and Kp1(-)/ lineage $\mathrm{C}$ for $T$. rangeli (Fig. 2, 3). Both results concur with previously conducted studies on the genetic characterization of human trypanosomes in Panama [29-31]. In other Latin American endemic regions, TcI is the most frequently $T$. cruzi DTU in sylvatic cycles, but it is also found in domestic epidemiological scenarios [32]. On the other hand, this study describes the presence of $T$. rangeli $\mathrm{Kp} 1$ (-)/lineage $\mathrm{C}$ in $R$. pallescens from Panama, an expected result considering the geographical distribution and the association with the "pallescens group" described for this genotype [33]. However, phylogenetic analyzes show some differences between the $T$. rangeli evaluated and the cox 2 sequences so far described for T. rangeli $\mathrm{Kp} 1(-)$ isolates (Fig. 3). In this regard, it is important to consider the reported association between genetic groups of $T$. rangeli and some Rhodnius species conditioned to specific geographical regions and different ecotopes [34]. In this sense, subtyping these Tc1 and Kp1(-) parasites $[35,36]$ must also be considered for a better knowledge of the intraspecific genetic variability adopted by the trypanosomes that infect $R$. pallescens in the mountainous region of Santa Fe, Panama.

\section{Conclusions}

In this report we provide information on basic phenotypic characteristics, trypanosome infection and trypanosome genotypes infecting a darker chromatic population of $R$. pallescens found in a recently described area that is endemic for Chagas disease in Panama. These adult triatomines showed high trypanosome infection rates, particularly with $T$. rangeli. A better evaluation of the consequences of $T$. rangeli infection in this chromatic variant of $R$. pallescens is needed. The genetic diversity of these trypanosomes was partially studied. TcI was the only DTU detected for T. cruzi, and Kp1(-)/lineage C for T. rangeli. However, based on cox 2 sequences analysis, it is suggested that the described $T$. rangeli genetic variant needs to be further characterized using other molecular markers.

\section{Abbreviations}

BLAST: Basic Local Alignment Search Tool; cox2: Cytochrome c oxidase subunit 2; DTU: Discrete typing unit; RFLP: Restriction fragment length polymorphism; Tcl: Trypanosoma cruzi lineage I 


\section{Acknowledgements}

We acknowledge with appreciation the field and technical assistance of Roberto Rojas and José Montenegro.

\section{Funding}

This investigation received financial support from the Secretaría Nacional de Ciencia, Tecnología e Innovación (SENACYT, Panamá) project COL11-043, Sistema Nacional de Investigación (SNI, SENACYT), and the Instituto Conmemorativo Gorgas de Estudios de la Salud (ICGES), Panamá.

\section{Availability of data and materials}

The datasets used and/or analysed during the current study are available from the corresponding author on reasonable request. The sequences were submitted to the GenBank database under the accession numbers MH349443-MH349451 (T. cruzi) and MH349452MH349459 (T. rangeli).

\section{Authors' contributions}

AS, NG and JEC conceived the study and wrote the manuscript. AMS, VP and W performed field and laboratory studies. All authors read and approved the final manuscript.

\section{Ethics approval and consent to participate} Not applicable.

\section{Consent for publication}

Not applicable.

\section{Competing interests}

The authors declare that they have no competing interests. AS and JEC are members of the Sistema Nacional de Investigación (SNI), SENACYT, Panamá.

\section{Publisher's Note}

Springer Nature remains neutral with regard to jurisdictional claims in published maps and institutional affiliations.

\section{Author details}

${ }^{1}$ Instituto Conmemorativo Gorgas de Estudios de la Salud (ICGES), Ciudad de Panamá, Panamá. ${ }^{2}$ Centro de Investigación y Diagnóstico de Enfermedades Parasitarias (CIDEP), Facultad de Medicina, Universidad de Panamá, Ciudad de Panama, Panamá. ${ }^{3}$ Department of Veterinary Pathology, University of Georgia College of Veterinary Medicine, Athens, Georgia 30602, USA.

Received: 16 January 2018 Accepted: 9 July 2018

Published online: 16 July 2018

\section{References}

1. Rodriguez IG, Loaiza JR. American trypanosomiasis, or Chagas disease, in Panama: a chronological synopsis of ecological and epidemiological research. Parasit Vectors. 2017;10:459.

2. Garisto-Risco JD, Saldaña A, Zebede S, Calzada JE. Cardiac alterations in seropositive patients with chagasic infection in Panama. Rev Esp Cardiol. 2009:62:947-8.

3. Vallejo GA, Suárez Y, Olaya JL, Gutiérrez SA, Carranza JC. Trypanosoma rangeli: un protozoo infectivo y no patógeno para el humano que contribuye al entendimiento de la transmisión vectorial y la infección por Trypanosoma cruzi, agente causal de la enfermedad de Chagas. Rev Acad Colomb Cienc Exact Fis Nat. 2015:39:111-22.

4. Saldaña A, Sousa OE. Trypanosoma rangeli: epimastigote immunogenicity and cross-reaction with Trypanosoma cruzi. J Parasitol. 1996:82:363-6.

5. Mendez E, Sousa OE. Identificación y distribución de los triatominos de Panama (Hemíptera: Reduviidae: Triatominae). Rev Med Panama. 1979;4: 258-80

6. Brenière SF, Waleckx E, Barnabé C. Over six thousand Trypanosoma cruzi strains classified into discrete typing units (DTUs): attempt at an inventory. PLoS Negl Trop Dis. 2016;10:e0004792.

7. Saldaña A, Pineda V, Martinez I, Santamaria G, Santamaria AM, Miranda A, et al. A new endemic focus of Chagas disease in the northern region of Veraguas Province, Western Half Panama, Central America. PLoS One 2012;7: e34657.
8. Calzada JE, Pineda V, Montalvo E, Alvarez D, Santamaría AM, Samudio F, et al. Human trypanosome infection and the presence of intradomicile Rhodnius pallescens in the western border of the Panama Canal, Panama, Am J Trop Med Hyg 2006;74:762-765.

9. Pavia PX, Vallejo GA, Montilla M, Nicholls RS, Puerta CJ. Detection of Trypanosoma cruzi and Trypanosoma rangeli infection in triatomine vectors by amplification of the histone H2A/SIRE and the sno-RNA-Cl1 genes. Rev Inst Med Trop Sao Paulo. 2007;49:23-30.

10. de Sá AR, Steindel M, Demeu LM, Luckemeyer DD, Grisard EC, Neto QA, et al. Cytochrome oxidase subunit 2 gene allows simultaneous detection and typing of Trypanosoma rangeli and Trypanosoma cruzi. Parasit Vectors 2013; 6:363.

11. Lent H, Wygodzinsky P. Revision of the Triatominae (Hemiptera:Reduviidae) and their significance as vectors of Chagas disease. Bull Am Mus Nat Hist. 1979;163:123-520.

12. Abad-Franch F, Lima MM, Sarquis $O$, Gurgel-Gonçalves $R$, Sánchez-Martín M, Calzada J, et al. On palms, bugs, and Chagas disease in the Americas. Acta Trop. 2015;151:126-41.

13. da Rosa JA, Justino HHG, Nascimento JD, Mendonça VJ, Rocha CS, de Carvalho DB, et al. A new species of Rhodnius from Brazil (Hemiptera, Reduviidae, Triatominae). ZooKeys. 2017:675:1-25.

14. Dias FBS, Bezerra CM, De Menezes Machado EM, Casanova C, Diotaiuti L. Ecological aspects of Rhodnius nasutus Stål, 1859 (Hemiptera: Reduviidae: Triatominae) in palms of the Chapada do Araripe in Ceará, Brazil. Mem Inst Oswaldo Cruz. 2008;103:824-30.

15. Dias FBS, Jaramillo N, Diotaiuti L. Description and characterization of the melanic morphotype of Rhodnius nasutus Stål, 1859 (Hemiptera: Reduviidae: Triatominae). Rev Soc Bras Med Trop. 2014;47:637-41.

16. Gaunt M, Miles $M$. The ecotopes and evolution of triatomine bugs (Triatominae) and their associated trypanosomes. Mem Inst Oswaldo Cruz. 2000;95:557-65

17. Noireau F, Flores R, Gutierrez T, Dujardin JP. Detection of sylvatic dark morphs of Triatoma infestans in the Bolivian Chaco. Mem Inst Oswaldo Cruz. 1997;92:583-4.

18. Almeida CE, Pacheco RS, Noireau F, Costa J. Triatoma rubrovaria (Blanchard, 1843) (Hemiptera: Reduviidae) I: Isoenzymatic and chromatic patterns of five populations from the State of Rio Grande do Sul, Brazil. Mem Inst Oswaldo Cruz. 2002;97:829-34.

19. Costa J, Cordeiro Correia N, Neiva VL, Gonçalves TCM, Felix M. Revalidation and redescription of Triatoma brasiliensis macromelasoma Galvão, 1956 and an identification key for the Triatoma brasiliensis complex (Hemiptera: Reduviidae: Triatominae). Mem Inst Oswaldo Cruz. 2013:108:785-9.

20. Dos Santos Souza E, Von Atzingen NCB, Furtado MB, De Oliveira J, Nascimento JD, Vendrami DP, et al. Description of Rhodnius marabaensis sp. n. (Hemiptera, Reduviidade, Triatominae) from Pará State, Brazil. ZooKeys. 2016:621:45-62.

21. Pineda V, Montalvo E, Alvarez D, Santamaría AM, Calzada JE, Saldaña A. Feeding sources and trypanosome infection index of Rhodnius pallescens in a Chagas disease endemic area of Amador County, Panama. Rev Inst Med Trop Sao Paulo. 2008:50:113-6.

22. Calzada JE, Pineda V, Garisto JD, Samudio F, Santamaria AM, Saldaña A. Human trypanosomiasis in the eastern region of the Panama Province: new endemic areas for Chagas disease. Am J Trop Med Hyg. 2010;82: $580-2$.

23. Ocaña-Mayorga S, Aguirre-Villacis F, Pinto CM, Vallejo GA, Grijalva MJ. Prevalence, genetic characterization, and 185 small subunit ribosomal RNA diversity of Trypanosoma rangeli in triatomine and mammal hosts in endemic areas for chagas disease in Ecuador. Vector Borne Zoonotic Dis. 2015;15:732-42.

24. Ramirez LE, Lages-Silva E, Alvarenga-Franco F, Matos A, Vargas N, Fernandes $\mathrm{O}$, et al. High prevalence of Trypanosoma rangeli and Trypanosoma cruzi in opossums and triatomids in a formerlyendemic area of Chagas disease in Southeast Brazil. Acta Trop. 2002;84: 189-98.

25. Gurgel-Gonçalves R, Cura C, Schijman AG, Cuba CA. Infestation of Mauritia flexuosa palms by triatomines (Hemiptera: Reduviidae), vectors of Trypanosoma cruzi and Trypanosoma rangeli in the Brazilian savanna. Acta Trop. 2012;121:105-11.

26. Ferreira LL, Lorenzo MG, Elliot SL, Guarneri A. A standardizable protocol for infection of Rhodnius prolixus with Trypanosoma rangeli, which mimics 
natural infections and reveals physiological effects of infection upon the insect. J Invertebr Pathol. 2010;105:91-7.

27. Peterson JK, Graham AL. What is the "true" effect of Trypanosoma rangeli on its triatomine bug vector? J Vector Ecol. 2016;41:27-33.

28. Gottdenker NL, Chaves LF, Caldez JE, Peterson JK, Santamaría A, Pineda V, et al. Trypanosoma cruzi and Trypanosoma rangeli co-infection patterns in insect vectors vary across habitat types in a fragmented forest landscape. Parasitol Open. 2016;2:1-10.

29. Sousa OE, Samudio F, de Juncá C, Calzada JE. Molecular characterization of human Trypanosoma cruzi isolates from endemic areas in Panama. Mem Inst Oswaldo Cruz. 2006;101:455-7.

30. Samudio F, Ortega-Barría E, Saldaña A, Calzada J. Predominance of Trypanosoma cruzi I among Panamanian sylvatic isolates. Acta Trop. 2007; 101:178-81.

31. Salazar-Antón F, Urrea DA, Guhl F, Arévalo C, Azofeifa G, Urbina A, et al. Trypanosoma rangeli genotypes association with Rhodnius prolixus and $R$. pallescens allopatric distribution in Central America. Infect Genet Evol. 2009; 9:1306-10.

32. Zingales B, Miles MA, Campbell DA, Tibayrenc M, Macedo AM, Teixeira MMG, et al. The revised Trypanosoma cruzi subspecific nomenclature: rationale, epidemiological relevance and research applications. Infect Genet Evol. 2012;12:240-53.

33. Vallejo GA, Guhl F, Schaub GA. Triatominae-Trypanosoma cruzi/T. rangeli: vector-parasite interactions. Acta Trop. 2009:110:137-47.

34. Da Silva FM, Noyes H, Campaner M, Junqueira AC, Coura JR, Añez N, et al. Phylogeny, taxonomy and grouping of Trypanosoma rangeli isolates from man, triatomines and sylvatic mammals from widespread geographical origin based on SSU and ITS ribosomal sequences. Parasitology 2004;129: 549-561

35. Sincero TCM, Stoco PH, Steindel M, Vallejo GA, Grisard EC. Trypanosoma rangeli displays a clonal population structure, revealing a subdivision of KP1(-) strains and the ancestry of the Amazonian group. Int J Parasitol. 2015:45:225-35.

36. Dorn PL, McClure AG, Gallaspy MD, Waleckx E, Woods AS, Monroy MC, et al. The diversity of the Chagas parasite, Trypanosoma cruzi, infecting the main Central American vector, Triatoma dimidiata, from Mexico to Colombia. PLoS Negl Trop Dis 2017;11:1-15.

Ready to submit your research? Choose BMC and benefit from:

- fast, convenient online submission

- thorough peer review by experienced researchers in your field

- rapid publication on acceptance

- support for research data, including large and complex data types

- gold Open Access which fosters wider collaboration and increased citations

- maximum visibility for your research: over $100 \mathrm{M}$ website views per year

At $\mathrm{BMC}$, research is always in progress.

Learn more biomedcentral.com/submissions 